(2) Open Access Full Text Article

\title{
Expression of VEGF in human conjunctival melanoma analyzed with immunohistochemistry
}

This article was published in the following Dove Press journal: Clinical Ophthalmology

\author{
Satoru Kase \\ Iku Kikuchi \\ Susumu Ishida \\ Department of Ophthalmology, \\ Faculty of Medicine and Graduate \\ School of Medicine, Hokkaido \\ University, Sapporo 060-8638, Japan
}

Correspondence: Satoru Kase Department of Ophthalmology, Faculty of Medicine and Graduate School of Medicine, Hokkaido University, N-15, W-7, Kita-ku, Sapporo 060-8638, Japan $\mathrm{Tel}+8$ I I | 7065944

Fax +8I II 7065948

Email kaseron@med.hokudai.ac.jp
Purpose: The aim of this study was to examine the immunolocalization of VEGF-A and CD34, a marker of endothelial cells, in human conjunctival melanoma.

Methods: This study retrospectively analyzed primary conjunctival melanoma patients who underwent surgical resection of the tumor. All excised tissues were fixed with paraformaldehyde and embedded in paraffin, which were then submitted for immunohistochemistry with anti-VEGF and CD34 antibodies.

Results: The study sample comprised 4 female and two male melanoma patients. The age of the patients ranged from 64 to 84 (average age, 73) years. Histopathology of the surgically resected tumor tissues demonstrated accumulation of polygonal atypical malignant cells producing melanin. Cytoplasmic immunoreactivity for VEGF was clearly observed in tumor cells of all six tumors. In contrast, CD34-positive endothelial cells were less marked in the melanoma tissues than in the adjacent noncancerous subconjunctival stroma.

Conclusion: VEGF immunoreactivity was observed in conjunctival melanoma tissues, in which endothelial cells were hardly observed. These results suggest that although VEGF is expressed, conjunctival melanoma is a hypovascular tumor.

Keywords: conjunctival melanoma, immunohistochemistry, microvessels, VEGF

\section{Introduction}

Conjunctival melanoma is a life-threatening ocular surface tumor with worldwide incidence, although the tumor is rarely found in Japanese population. Conjunctival melanoma can arise from primary acquired melanosis (PAM), nevus, or de novo. Conjunctival melanoma has a 5-year survival rate of over $80 \%,{ }^{1}$ but can develop lymph node and distant metastases such as pulmonary and parotid gland metastases. We recently reported that adjuvant local chemotherapy using topical interferon alpha- $2 \mathrm{~b}$ resulted in preservation of globes in patients with conjunctival melanoma; however, not all patients showed good response to the local therapy. ${ }^{2}$ Therefore, further additional treatment targets should be developed to save the patients' vision and life. It has been reported that intratumoral lymphatic vessels were proliferative, which possibly correlated with tumor growth and a worse patients' prognosis in conjunctival melanoma. ${ }^{3}$

VEGF-A is a pleiotropic protein, which was historically identified as a tumor angiogenic factor. VEGF can be expressed and secreted from various tumor cells and the stroma, which stimulates endothelial cells and increases the number of microvessels in tumor tissues. ${ }^{4}$ The increased microvessels are considered to provide oxygen to the tumor tissue and allow the tumor cells to escape from apoptosis. Recent studies have proved that VEGF induced not only tumor angiogenesis and vascular permeability but also tumorigenesis, the latter of which might be independent of angiogenesis. ${ }^{4}$ 
It has been reported that cultured conjunctival melanoma cells express $V E G F$ gene and protein; ${ }^{5}$ however, little is known about the expression of VEGF and the formation of microvessels in human conjunctival melanoma.

The aim of this study is to examine VEGF immunolocalization and microvessel density in human conjunctival melanoma.

\section{Materials and methods}

This was a retrospective observational study. We enrolled patients with histology-proven primary conjunctival melanoma who had been treated in the Department of Ophthalmology, Hokkaido University Hospital, from March 2009 to November 2015, based on the medical records. The study sample comprised six patients who underwent local resection of tumor tissues. The tissues were resected with safety margins of 1-2 mm out of the elevated lesions based on no-touch technique. ${ }^{6}$ Patients with histology-proven conjunctival nevus and PAM were excluded from the study. Each tumor was classified according to TNM classification of the American Joint Committee on Cancer (AJCC), eighth edition. This study was approved by the institutional review board (IRB) of Hokkaido University (IRB number: 015-0062) and was conducted in compliance with the Declaration of Helsinki. The protocol was described in the website of the hospital, and subjects were provided with the opportunity to opt out, and therefore, no new consent was required from the patients.

\section{Histology and immunohistochemistry}

The melanoma tissues were fixed with $4 \%$ paraformaldehyde immediately after surgical excision in the operating room. After the excised tumor tissues were embedded in paraffin, $5 \mu \mathrm{m}$-thick sections were cut. The slides were dewaxed, rehydrated, and rinsed in PBS twice for 10 minutes. Slides were submitted for H\&E staining and immunohistochemistry. As a pretreatment for immunohistochemistry, microwavebased antigen retrieval was performed in $10 \mathrm{mM}$ citrate buffer ( $\mathrm{pH}$ 6.0) after demelanization by incubation with $1 \mathrm{~g}$ phosphoric acid in $100 \mathrm{~mL}$ of $3 \%$ hydrogen peroxide for 4 hours. These slides were immersed in $3 \%$ hydrogen peroxide for 10 minutes and then in normal goat serum for 30 minutes. Then, the sections were incubated with anti-VEGF (dilution 1:50, A-20; Santa Cruz Biotechnology Inc., Dallas, TX, USA) and anti-CD34 (dilution 1:50, M7165; Dako Japan Inc) antibodies at $4{ }^{\circ} \mathrm{C}$ overnight. The secondary antibody reaction was carried out with anti-rabbit antibody (EnVision System HRPlabeled polymer; Dako Japan Inc) for 30 minutes at room temperature. Positive signals were visualized using HistoGreen (LINARIS; catalog number: E109) as a substrate. Slides were examined using a Keyence BZ-9000 (Keyence, Osaka, Japan) microscope. The tumor cells and the adjacent choroidal vessels of the enucleated eyes with choroidal melanoma ${ }^{7}$ served as a positive control of VEGF and CD34, respectively.

\section{Evaluation of immunohistochemical results}

To evaluate VEGF expression, the number of tumor cells with cytoplasmic immunoreactivity was directly counted under light microscope at high magnification (objective $\times 40$ ) in two or three fields in each section, which was then calculated as positive rate (\%) of total tumor cells. Intratumoral microvessel density was calculated according to the previous reports. ${ }^{8,9}$ Briefly, the number of CD34-immunopositive microvessels in the tumor tissues was directly counted under light microscope (objective $\times 40$ ). The counting was done in two or three high-power fields, and the numbers were then averaged to determine the microvessel density.

\section{Results}

Table 1 summarizes the clinicopathological features of conjunctival melanoma patients examined in this study. The sample comprised four female and two male melanoma patients. The age of the patients ranged from 65 to 84 (average age, 74) years. Slit lamp examination demonstrated

Table I Clinicopathological profile and VEGF-immunopositive rate of patients with conjunctival melanoma

\begin{tabular}{|c|c|c|c|c|c|c|c|}
\hline Case & Age (years) & Sex & Genesis & Location & Pigmentation & TNM classification & VEGF (\%) \\
\hline 1 & 65 & $\mathrm{~F}$ & Nevus & Limbs & High & PTIaNOMO & 87 \\
\hline 2 & 77 & $\mathrm{~F}$ & PAM & Bulbar conjunctiva & High & PTIbNOMO & 73 \\
\hline 3 & 78 & $M$ & PAM & $\begin{array}{l}\text { Balbar conjunctiva, } \\
\text { palpebral conjunctiva }\end{array}$ & High & PT3bNOMO & 75 \\
\hline 4 & 84 & $\mathrm{~F}$ & PAM & $\begin{array}{l}\text { Bulbar conjunctiva, } \\
\text { lacrimal caruncle }\end{array}$ & High & $\mathrm{pT} 2 \mathrm{aNOMO}$ & 73 \\
\hline 5 & 66 & $\mathrm{~F}$ & De novo & Bulbar conjunctiva & High & PTIaNOMO & 33 \\
\hline 6 & 73 & $M$ & Nevus & Bulbar conjunctiva & Low & PTIaNOMO & 32 \\
\hline
\end{tabular}

Abbreviations: $F$, female; $M$, male; PAM, primary acquired melanosis. 

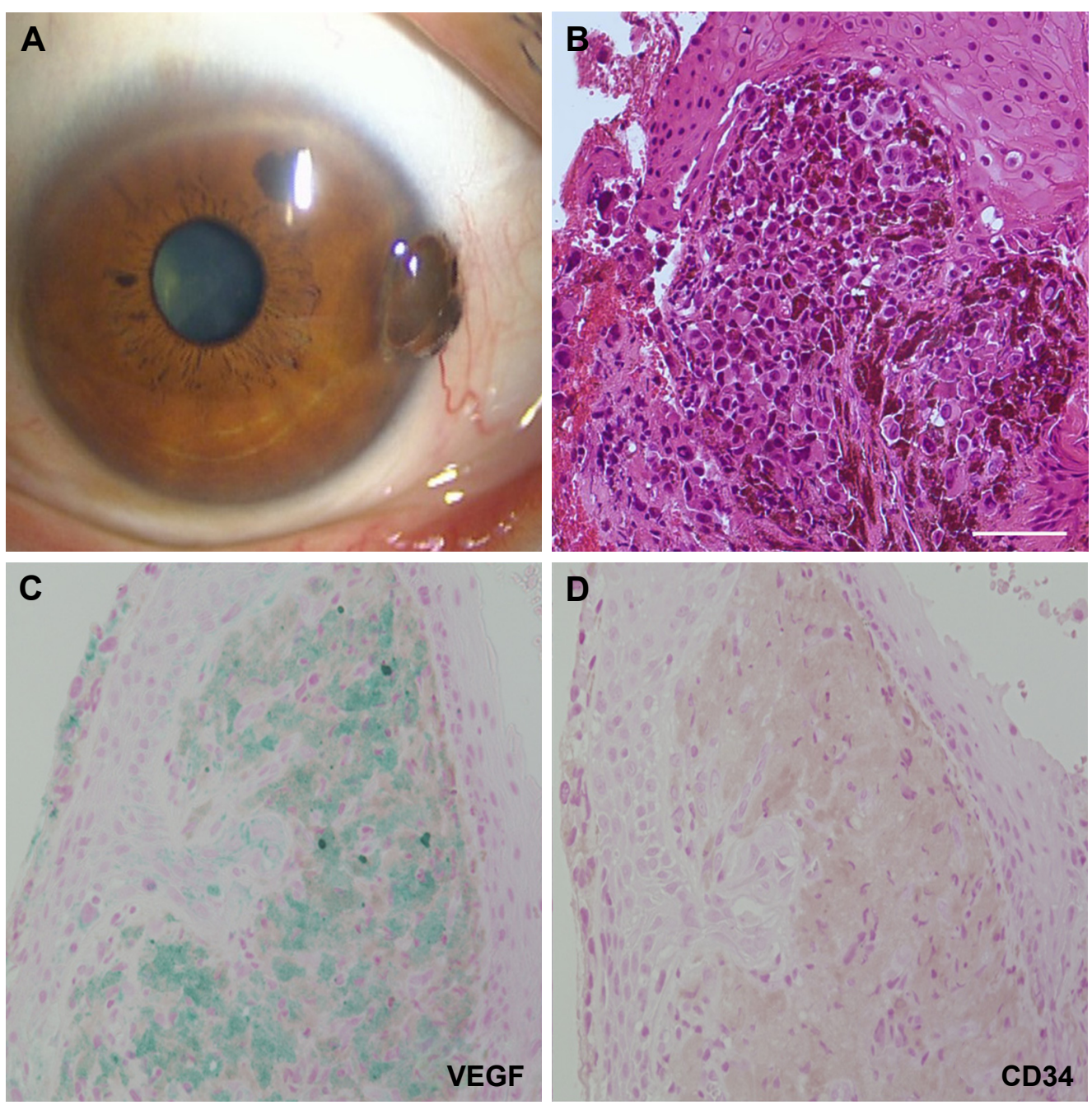

Figure I A representative case of conjunctival melanoma in a 65-year-old female.

Notes: The pigmented tumor is noted in the corneal limbs with abnormal conjunctival vessels (A). Histopathology of the resected tumor reveals epithelioid-type melanoma cells infiltrated beneath the conjunctival epithelium (B). VEGF immunoreactivity is clearly detected in the cytoplasm of tumor cells as a greenish coloration (C). In contrast, CD34-positive blood vessels are not detected in the tumor tissue (D). A bar indicates $50 \mu \mathrm{m}$; magnification $\times 40$.

a blackish nodule in the conjunctiva (Figures $1 \mathrm{~A}$ and $2 \mathrm{~A}$ ) in all the patients. Three tumors arose from PAM (Figure 2A), two from nevus (Figure 1A), and one from de novo. Histopathology of the surgically resected tumor tissues demonstrated accumulation of polygonal atypical malignant cells producing melanin (Figures 1B and 2B). Cytoplasmic immunoreactivity for VEGF was clearly observed as greenish coloration in a variety of conjunctival melanoma cells (Figures $1 \mathrm{C}$ and 2C). Four of the six cases showed a high VEGF-immunopositive rate of over 70\% (Cases 1-4 in Table 1). In contrast, the other two cases (Cases 5 and 6 in Table 1) revealed a VEGF-immunopositive rate of about $30 \%$, whereas none of the cases showed negative immunoreactivity for VEGF. In contrast, CD34-positive endothelial cells were less marked in the melanoma tissues (Figures 1D and 2D). Intratumoral microvessel density was less than one vessel $/ \mathrm{mm}^{2}$ in every case examined, while a variety of CD34-positive blood vessels existed in the adjacent noncancerous subconjunctival stroma (Figure 2D).

\section{Discussion}

This study, for the first time, demonstrated VEGF immunoreactivity in tumor cells of human conjunctival melanoma tissues. Our data are also consistent with the laboratory data showing VEGF expression in cultured melanoma cells derived from the conjunctiva. ${ }^{5}$ However, it still remains controversial how the expressed VEGF pathologically correlates with angiogenesis in melanoma tissues. Simonetti et al showed that intratumoral microvessel density was correlated with increased VEGF expression in oral melanoma tissues. ${ }^{10}$ On the other hand, Salven et al proved no association between intratumoral microvessel density and VEGF expression in 

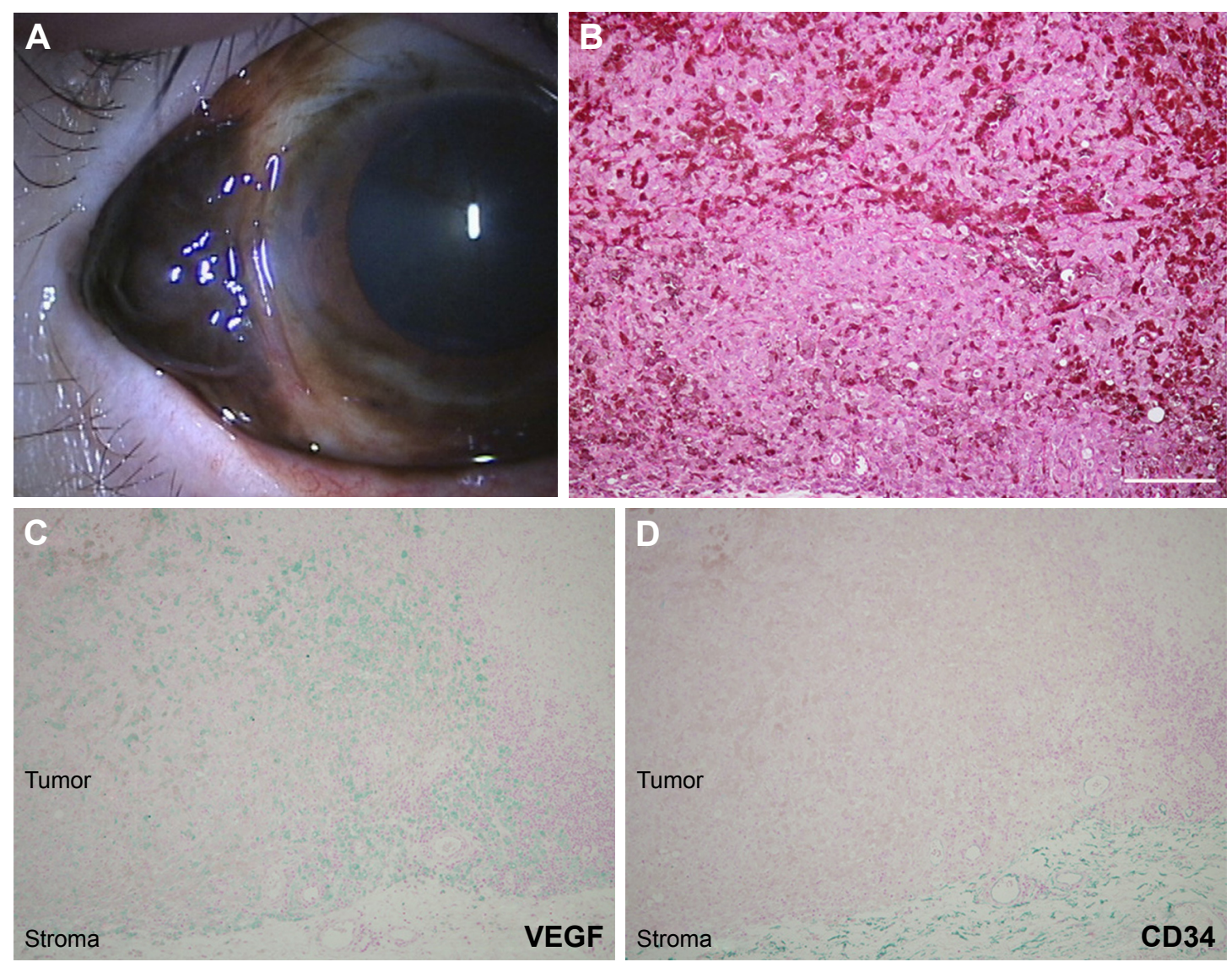

Figure 2 Another representative case of conjunctival melanoma in an 84-year-old female.

Notes: A marked pigmented elevation is observed in the temporal bulbar conjunctiva (A). There are multiple melanosis lesions around the tumor. Histopathology demonstrates mixed cell-type malignant melanoma having atypical cells with melanin production (B). VEGF immunoreactivity is clearly observed in the tumor tissue, whereas the immunoreactivity is not apparent in the adjacent noncancerous stroma (C). CD34-positive blood vessels are markedly identified in the noncancerous conjunctival stroma, whereas the endothelial cells are hardly detected in the tumor tissue (D). A bar indicates $50 \mu \mathrm{m}$; magnification $\times 10$.

primary and metastatic systemic melanoma tissues. ${ }^{11}$ This study showed that the number of CD34-positive intratumoral microvessels was quite low in conjunctival melanoma tissues, which was less marked than adjacent normal conjunctiva. These data suggest that conjunctival melanoma is characterized by a hypovascular tumor, although VEGF immunoreactivity was detected in all the tissues examined.

Several authors have shown that VEGF is responsible for the tumor development and metastasis in patients with malignant melanoma. ${ }^{11-13}$ Recently, Wan et al demonstrated that genifitib, an inhibitor of epidermal growth factor, could suppress cultured melanoma cell proliferation through downregulation of VEGF gene and protein expressions. ${ }^{14}$ However, it remains unknown whether VEGF-driven angiogenesis affects the tumor growth of melanoma. Although it is well known that VEGF leads to angiogenesis in various solid tumors, VEGF also plays an important role in tumorigenesis, which cannot be associated with pathological neovascularization. ${ }^{4}$ Therefore, this study suggests that VEGF might be expressed during the tumorigenesis of human conjunctival melanoma, which is independent of tumor angiogenesis.

Recent studies have shown that VEGF is a promising therapeutic target for human diseases. In fact, bevacizumab and ranibizumab, two anti-VEGF agents, have been safely used for patients with neovascular age-related macular degeneration. ${ }^{15,16}$ Moreover, VEGF may hold a key to a novel therapeutic target for malignant melanoma. VEGF was certainly expressed in cultured uveal melanoma cells, and the cell growth was suppressed under bevacizumab and ranibizumab stimuli. ${ }^{17,18}$ Taken together, it is likely that anti-VEGF therapy can regulate not only neovascular diseases of the eye but also tumor cell proliferation in uveal melanoma cells. Corrie et al have shown that adjuvant antiVEGF therapy (bevacizumab) contributed to improvement of disease-free survival in melanoma patients with a high risk of recurrence. ${ }^{19,20}$ In contrast, although anti-VEGF therapy might not be straightforward in contribution to regulation of primary uveal melanoma, ${ }^{21,22}$ these results suggest that anti-VEGF 
therapy might be considered one of the potential therapeutic strategies in patients with conjunctival melanoma.

There are limitations in this study. First, the number of samples examined is very small, since conjunctival melanoma is a rare malignant tumor in Japanese population, because of which, clinicopathological studies on this tumor have not progressed well. Second, although this study indicated that VEGF might play a role in tumorigenesis, VEGF expression could not be examined in premalignant lesions such as PAM and nevus. Further, molecular pathways regarding VEGF signaling are still uncertain. Therefore, further cell biological approaches are needed to examine VEGF receptors and the downstream molecular pathways in conjunctival melanoma as well as the premalignant lesions.

\section{Disclosure}

The authors report no conflicts of interest in this work.

\section{References}

1. Paridaens AD, Minassian DC, Mccartney AC, Hungerford JL. Prognostic factors in primary malignant melanoma of the conjunctiva: a clinicopathological study of 256 cases. Br J Ophthalmol. 1994;78(4): 252-259.

2. Kikuchi I, Kase S, Ishijima K, Ishida S. Long-term follow-up of conjunctival melanoma treated with topical interferon alpha-2b eye drops as adjunctive therapy following surgical resection. Graefes Arch Clin Exp Ophthalmol. 2017;255(11):2271-2276.

3. Heindl LM, Hofmann-Rummelt C, Adler W, et al. Prognostic significance of tumor-associated lymphangiogenesis in malignant melanomas of the conjunctiva. Ophthalmology. 2011;118(12):2351-2360.

4. Goel HL, Mercurio AM. VEGF targets the tumour cell. Nat Rev Cancer. 2013;13(12):871-882.

5. Refaian N, Schlereth SL, Koch KR, et al. Comparing the hem- and lymphangiogenic profile of conjunctival and uveal melanoma cell lines. Invest Ophthalmol Vis Sci. 2015;56(9):5691-5697.

6. Shields JA, Shields CL, De Potter P. Surgical management of circumscribed conjunctival melanomas. Ophthalmic Plast Reconstr Surg. 1998;14(3):208-215.

7. Xu Q, Zhao GQ, Zhao J, et al. Expression and significance of factors related to angiogenesis in choroidal melanoma. Int J Ophthalmol. 2011;4(1):49-54
8. Kase S, Osaki M, Honjo S, et al. Expression of cyclo-oxygenase-2 is correlated with high intratumoral microvessel density and low apoptotic index in human esophageal squamous cell carcinomas. Virchows Arch. 2003;442(2):129-135.

9. Kinoshita S, Kase S, Ando R, et al. Expression of vascular endothelial growth factor in human ocular adnexal lymphoma. Invest Ophthalmol Vis Sci. 2014;55(6):3461-3467.

10. Simonetti O, Lucarini G, Rubini C, et al. Microvessel density and VEGF, HIF-1 $\alpha$ expression in primary oral melanoma: correlation with prognosis. Oral Dis. 2013;19(6):620-627.

11. Salven P, Heikkilä P, Joensuu H. Enhanced expression of vascular endothelial growth factor in metastatic melanoma. Br J Cancer. 1997; 76(7):930-934.

12. Ugurel $\mathrm{S}$, Rappl G, Tilgen W, Reinhold U. Increased serum concentration of angiogenic factors in malignant melanoma patients correlates with tumor progression and survival. J Clin Oncol. 2001;19(2):577-583.

13. Ascierto PA, Leonardi E, Ottaiano A, Napolitano M, Scala S, Castello G. Prognostic value of serum VEGF in melanoma patients: a pilot study. Anticancer Res. 2004;24(6):4255-4258.

14. Wan X, Zhu Y, Zhang L, Hou W. Gefitinib inhibits malignant melanoma cells through the VEGF/AKT signaling pathway. Mol Med Rep. 2018;17(5):7351-7355.

15. Moja L, Lucenteforte E, Kwag KH, et al. Systemic safety of bevacizumab versus ranibizumab for neovascular age-related macular degeneration. Cochrane Database Syst Rev. 2014;(9):CD011230.

16. Abouammoh M, Sharma S. Ranibizumab versus bevacizumab for the treatment of neovascular age-related macular degeneration. Curr Opin Ophthalmol. 2011;22(3):152-158

17. Koch KR, Refaian N, Hos D, et al. Autocrine impact of VEGF-A on uveal melanoma cells. Invest Ophthalmol Vis Sci. 2014;55(4):2697-2704.

18. Li J, Cui Y, Wang Q, et al. The proliferation of malignant melanoma cells could be inhibited by ranibizumab via antagonizing VEGF through VEGFR1. Mol Vis. 2014;20:649-660.

19. Corrie PG, Marshall A, Nathan PD, et al; AVAST-M Investigators Adjuvant bevacizumab for melanoma patients at high risk of recurrence: survival analysis of the AVAST-M trial. Ann Oncol. 2018;29(8): $1843-1852$.

20. Corrie PG, Marshall A, Dunn JA, et al. Adjuvant bevacizumab in patients with melanoma at high risk of recurrence (AVAST-M): preplanned interim results from a multicentre, open-label, randomised controlled phase 3 study. Lancet Oncol. 2014;15(6):620-630.

21. el Filali M, Ly LV, Luyten GP, et al. Bevacizumab and intraocular tumors: an intriguing paradox. Mol Vis. 2012;18:2454-2467.

22. el Filali M, Missotten GS, Maat W, et al. Regulation of VEGF-A in uveal melanoma. Invest Ophthalmol Vis Sci. 2010;51(5):2329-2337.
Clinical Ophthalmology

\section{Publish your work in this journal}

Clinical Ophthalmology is an international, peer-reviewed journal covering all subspecialties within ophthalmology. Key topics include: Optometry; Visual science; Pharmacology and drug therapy in eye diseases; Basic Sciences; Primary and Secondary eye care; Patient Safety and Quality of Care Improvements. This journal is indexed on

\section{Dovepress}

PubMed Central and CAS, and is the official journal of The Society of Clinical Ophthalmology (SCO). The manuscript management system is completely online and includes a very quick and fair peer-review system, which is all easy to use. Visit http://www.dovepress.com/ testimonials.php to read real quotes from published authors. 